\title{
Could Monoamine Plasma Levels and Erythrocyte Membrane ATPase Activities at Birth Be Predictive for Future Hand Performance?
}

\author{
LARISSA TAKSER, DAVE CAMPAGNA, PHILIPPE BLOT, AND GUY HUEL
}

Institut National de la Santé et de la Recherche Médicale (INSERM-U472), Recherche en Épidemiologie et en Biostatistique, 94807 Villejuif, France [L.T., D.C., G.H.]; Health Investigations Branch, Division of Health Studies, Agency for Toxic Substances and Disease Registry (ATSDR), U.S. Department of Health and Human Services, Atlanta, Georgia, U.S.A. [D.C.]; and Hôpital Robert Debré, Paris, France [P.B.]

\section{ABSTRACT}

The monoamine and intracellular calcium systems are two major elements of nervous system functions. However, their role in human brain development is unclear. We studied the association between activity of monoamine and intracellular calcium systems during prenatal life and subsequent psychomotor performances in healthy children. We used prospective data from 247 children followed from birth through 6 y of age. Among those, 195 were examined at 9 mo using the Brunet-Lézine Scales, whereas 126 were examined at $3 \mathrm{y}$ and 100 at $6 \mathrm{y}$ using the McCarthy Scales of Children's Ability. A blood sample was collected from the umbilical cord to measure levels of dopamine and serotonin metabolites (homovanillic acid and 5-hydroxyindoleacetic acid, respectively) and ATPase activities $\left(\mathrm{Na}^{+} \mathrm{K}^{+}\right.$ATPase and $\mathrm{Ca}^{2+} \mathrm{Mg}^{2+}$-ATPase). The hand skill score at $6 \mathrm{y}$ of age was significantly and negatively correlated with ATPase activities and with monoamine metabolite concentrations. No other cognitive score was related to biochemical measures at birth. Results were adjusted for child's sex, mother's educational level, duration of labor, and tea consumption. Composite scores of ATPase activities and monoamine metabolite concentrations measured at birth explained $29 \%$ of hand skill score variance at $6 \mathrm{y}$. Our results demonstrate the importance of prenatal factors on monoaminergic and ATPase activities in early human psychomotor development. This study also suggests that specific psychometric measures such as fine motor tests may be a better developmental measurement to correlate with biochemical factors than general cognitive scales. (Pediatr Res 54: 358-363, 2003)

HVA, homovanillic acid

\section{Abbreviations}

5-HIAA, 5-hydroxyindoleacetic acid

MAO, monoamine oxidase

DBH, dopamine- $\beta$-hydroxylase

GCI, General Cognitive Index
Biochemical mechanisms involved in child development are only partly understood. Current knowledge is based on experimental and clinical studies, which are limited because of extrapolation from animal or human studies of small sample size.

The monoamine system, which includes the major neurotransmitters dopamine and serotonin, is likely to play an important role in brain development (1). Secretion of monoamines begins early in development of the human embryo (2). The perinatal period is characterized by high levels of secretion and oxidation of monoamines, with a subsequent decrease during early childhood (3). Monoamines have a neurotrophic effect on differentiation and growth of neural tube cells (4).

Received April 2, 2002; accepted February 3, 2003.

Correspondence: Larissa Takser, Ph.D., INSERM U472, 16 avenue Paul Vaillant Couturier, 94807 Villejuif Cedex, France; e-mail: takser@vjf.inserm.fr

Supported by the French Ministry of Research and Technology (Department "Biologie, Médecine et Santé, Action toxicologie": Grant DRAEI/93037).

DOI: 10.1203/01.PDR.0000077484.55921.A0
Insults occurring during the perinatal period, such as hypoxicischemic lesions, exposure to pharmaceutical substances, or infection, often lead to motor disturbances, which persist until school age (5). Severe asphyxia at birth is responsible for a reduction in dopamine neurons, and the intensity of this reduction is correlated with the degree of motor disturbance (6). The genetic syndromes that affect the metabolism of monoamines manifest themselves by motor disturbances starting at birth (7), and even an early therapeutic intervention that ensures normal cognitive development does not have a positive effect on manual dexterity (8). Upstream, metabolism of the monoamine system is regulated in part by the activity of MAO. Oxidation of dopamine is a known source of free radicals that are particularly harmful to membranes (9). A study showed that the activity of MAO is in part genetically predetermined and that its high activity can be associated, in normal subjects, with right hemisphere activity and a motor disinhibition (10). Additionally, numerous animal studies illustrated the adverse effects of maternal psychological stress and prenatal chemical 
exposures on functioning of the monoaminergic system and on postnatal behavior (1).

Intracellular calcium regulation is another major factor of nervous system development. Intracellular calcium plays an important role in neuronal growth and is one of the factors responsible for monoamine release (11). A gradient between intracellular and extracellular calcium is necessary for normal functioning of the cell. Intracellular calcium accumulation appears to mediate the neurotoxic effects of excitatory neurotransmitters and of other chemicals (e.g. metal ions and organotin compounds) (12). Intracellular calcium concentration depends on membrane ionic transport by enzymes such as $\mathrm{Na}^{+} \mathrm{K}^{+}$-ATPase and $\mathrm{Ca}^{2+} \mathrm{Mg}^{2+}$-ATPase of the plasma membrane, which are two of the determining factors of intracellular calcium regulation (13). $\mathrm{Ca}^{2+} \mathrm{Mg}^{2+}$-ATPase is directly involved in intracellular calcium regulation, being a specific enzyme for calcium extrusion through the plasma membrane. $\mathrm{Na}^{+} \mathrm{K}^{+}$-ATPase is responsible for the electrochemical gradient of the plasma membrane and for the flow of calcium ions through the voltage-dependent ion channel, as well as calcium transport through the $\mathrm{Na}^{+} / \mathrm{Ca}^{2+}$-exchanger (14). These two enzymes, $\mathrm{Na}^{+} \mathrm{K}^{+}$-ATPase and $\mathrm{Ca}^{2+} \mathrm{Mg}^{2+}$-ATPase, depend heavily on the presence of ATP, and can also indicate an energy deficit in the cell (15).

Based on this current knowledge we hypothesized that during the early period of rapid development of the nervous system, the monoaminergic system (serotonin and dopamine) and ATPase activities play a role in subsequent psychomotor development of the normal child. To our knowledge, no study has been carried out to elucidate the role of ATPase systems in child development, and only two longitudinal studies have examined the associations between healthy infant behavior and the monoaminergic system. Constantino and Murphy (16) reported a positive relationship between cerebrospinal fluid concentration of 5-HIAA and sociability score at 9 mo, but this result was not confirmed at age $18-21$ and 30 mo $(17,18)$. Rapoport et al. (19) found a positive correlation between DBH activity (an enzyme that converts dopamine into norepinephrine) and hyperactivity at 5 and $12 \mathrm{mo}$.

Using a prospective and epidemiologic approach, we took into account the effect of several known cofactors of human psychomotor development to study healthy children from birth to age 6. Plasma HVA and 5-HIAA measurements are largely used in clinical studies, and correlate with concurrent cerebrospinal fluid levels $(20,21)$. Erythrocyte ATPase activities $\left(\mathrm{Na}^{+} \mathrm{K}^{+}\right.$-ATPase and $\mathrm{Ca}^{2+} \mathrm{Mg}^{2+}$-ATPase) were used as models for neuronal membrane activities because isoforms observed in red blood cells also exist within neuronal membranes $(13,22)$. Erythrocyte ATPase activity is used to study intracellular calcium metabolism in bipolar disorders in psychiatric research (23). Therefore, we measured peripheral monoamine metabolites (HVA and 5-HIAA in blood plasma) and erythrocyte ATPase activities as possible surrogate indicators of the level of activity in the brain.

\section{METHODS}

Study population. Two hundred forty-seven Caucasian mother and newborn pairs were recruited in the Robert Debré
Maternity Hospital. This large pediatric hospital predominantly serves the suburbs and the northeastern section of Paris, France, and counts approximately 3000 births annually. Mothers consuming any illicit drugs were not included in the study. Stillbirths, multiple births, newborns with acute distress, pregnancies under regular drug treatment, and births by cesarean section or at a gestational age less than $37 \mathrm{wk}$ were excluded. All other newborns born between $0900 \mathrm{~h}$ and $1700 \mathrm{~h}$ were enrolled $2 \mathrm{~d}$ a week. Participation in the study was proposed only to women eligible with respect to the inclusion criteria. The study protocol was approved by the Robert Debré Maternity Hospital, and informed consent was signed by all participants. On average, participants had a high educational level, i.e. higher than the national level. Information regarding obstetrical history was obtained from medical records. Detailed information about drugs, coffee, tea consumption, and smoking during pregnancy was obtained from interview with each mother and the medical records. At age 9 mo, one child was excluded from the cohort because of medically confirmed congenital malformation and psychiatric signs.

Study design. A sample of blood was collected from the umbilical cord to measure monoamine metabolites and ATPase activities. Methods of $\mathrm{Ca}^{2+} \mathrm{Mg}^{2+}$-ATPase activity and monoamine metabolite measurements were reported previously (24, 25). The $\mathrm{Na}^{+} \mathrm{K}^{+}$-ATPase activity was measured by the same colorimetric method based on ouabain reaction. During followup, the children underwent three psychological examinations (at $9 \mathrm{mo}, 3 \mathrm{y}$, and $6 \mathrm{y}$ of age). From the initial population of 247 children at birth, 195 were examined at 9 mo, 126 at $3 \mathrm{y}$, and 100 at $6 \mathrm{y}$. Sixty percent of the initial population was lost to follow up only because of moving out, and not because of refusal to participate in the study.

Because it is the only psychomotor test validated in France that is suitable for the age group studied, psychological assessment was performed through the Brunet-Lézine Scales at 9 mo of age (26). The Brunet-Lézine Scales give the developmental quotient (QD), a global measure of psychomotor development. The McCarthy Scales of Children's Ability (27) were performed at 3 and $6 \mathrm{y}$ of age. The McCarthy Scales were standardized in 1975 based on a representative French population. The McCarthy GCI includes 15 tests and evaluates vocabulary, memory, quantitative, and perceptive abilities. The Motor Scale includes five motor tests, two of which are also included in the GCI.

Statistical analysis. The principal component analysis (FACTOR procedure) with orthogonal matrix rotation (Varimax) (28) was used to determine the relations within psychometric and biochemical variables. The STEPWISE procedure was performed to look for potential cofactors. Then, the relationships between the psychometric scores and biochemical factors were examined using multiple regression models (GLM procedure). All statistical analyses were performed using SAS version 8 (29).

\section{RESULTS}

Population characteristics and variables selected for analysis. Table 1 shows the characteristics of the mothers and those 
Table 1. Population characteristics

\begin{tabular}{lccc}
\hline & $\begin{array}{c}\text { Initial population at birth* } \\
(n=247)\end{array}$ & $\begin{array}{c}\text { Participants at 6 years* } \\
(n=100)\end{array}$ & $\begin{array}{c}\text { Nonparticipants at 6 years* } \\
(n=147)\end{array}$ \\
\hline Mother's age at delivery (y) & $29 \pm 4.1(23-37)$ & $30 \pm 3.9(24-38)$ & $29 \pm 4.2(23-36)$ \\
Smokers & $25 \%$ & $29 \%$ & $22 \%$ \\
Alcohol drinkers & $12 \%$ & $11 \%$ & $12 \%$ \\
Coffee drinkers & $37 \%$ & $42 \%$ & $33 \%$ \\
Tea drinkers & $19 \%$ & $19 \%$ & $18 \%$ \\
Mother's educational level (high) & $63 \%$ & $69 \%$ & $58 \%$ \\
Gestational age (wk) & $39.8 \pm 1.2(38-41)$ & $39.9 \pm 1.0(38-41)$ & $39.8 \pm 1.2(37-41)$ \\
Labor duration (h) & $6.1 \pm 2.6(2-10)$ & $6.0 \pm 2.6(2-10)$ & $6.1 \pm 2.5(3-10)$ \\
Male newborns & $55 \%$ & $56 \%$ & $55 \%$ \\
Birth weight $(\mathrm{g})$ & $3375 \pm 418(2720-4040)$ & $3387 \pm 410(2665-3980)$ & $3371 \pm 424(2720-4090)$ \\
Apgar score at 1 minute $(<8)$ & $4 \%$ & $3 \%$ & $4 \%$ \\
\hline
\end{tabular}

* Percentage or mean \pm SD (5th-95th percentiles).

There was no significant difference between the characteristics of children followed at 6 years and those lost to follow-up (nonparticipants).

of their children recruited at birth. The characteristics of the follow-up group were not significantly different from those of the original group.

Table 2 shows the means and standard deviations of the levels of monoamine metabolites and ATPase activities at birth, and the psychomotor scores at 9 mo, $3 \mathrm{y}$, and 6 y of age. In our population, the McCarthy GCI scores were approximately 20 points higher than the expected population mean because this sample was of high socioeconomic level and the Flynn effect (30) is not excluded.

In a principal component analysis of the items from the McCarthy motor scale, tests involving fine manual manipulation were correlated among themselves and constituted a first component (Table 3). A hand skill score was constructed summing up the $z$ scores (difference between observation's value and variable's mean, divided by variable's $\mathrm{SD}$ ) of the items that composed the first component. The hand skill score seems more specific as a measure of manual performance than the motor scale proposed by McCarthy. Mean age-adjusted hand skill score was $0.002(\mathrm{SD}, 2.3)$ at $3 \mathrm{y}$ and 0.04 (SD, 2.0) at $6 \mathrm{y}$.
Two general indices, the McCarthy GCI and the hand skill score, were selected for the analyses.

The monoamine and membrane ATPase measurements were found to form two scores: MONO and ATP (Table 4). The $z$ scores of HVA and 5-HIAA measures are summarized in the score MONO, and the $z$ scores of ATPase measures make up the score ATP. The MONO score reflects the degree of monoamine degradation, and the ATP score yields the activity of membrane active cationic transport. Both scores are positively correlated $(r=0.17, p=0.01, n=208)$.

Cofactor effects on retained variables. We tested the relationships among McCarthy GCI, hand skill, MONO, and ATP scores and potential cofactors. Stepwise regression was used to identify major cofactors with these scores as the dependent variables. Independent variables were mother's age, educational level, duration of labor, and consumption of tea, coffee, alcohol, and smoking during pregnancy, and child's sex, gestational age, and birth weight. Among 10 cofactors tested, only tea consumption during gestation was associated with both biologic and most psychometric scores. The relationship between the duration of labor and the MONO score confirms that

Table 2. Biologic characteristics at birth and psychomotor scores at 9 mo, 3 y and $6 y$ of age

\begin{tabular}{|c|c|c|c|}
\hline & $\begin{array}{c}\text { Initial population } \\
\text { at birth* } \\
(n=247)\end{array}$ & $\begin{array}{l}\text { Participants } \\
\text { at } 6 \text { years* } \\
(n=100)\end{array}$ & $\begin{array}{l}\text { Nonparticipants } \\
\text { at } 6 \text { years* } \\
(n=147)\end{array}$ \\
\hline \multicolumn{4}{|l|}{ Erythrocyte ATPase activity at birth $(\mathrm{nM} / \mathrm{mg} / \mathrm{h})$} \\
\hline $\mathrm{Ca}^{2+} \mathrm{Mg}^{2+}$-ATPase & $2683 \pm 674(245)$ & $2718 \pm 703(100)$ & $2659 \pm 655(145)$ \\
\hline \multicolumn{4}{|l|}{ Plasma monoamine metabolites at birth $(\mathrm{ng} / \mathrm{mL})$} \\
\hline HVA & $145.7 \pm 53.8(210)$ & $150.0 \pm 47.7(90)$ & $142.3 \pm 58.0(120)$ \\
\hline \multicolumn{4}{|l|}{9 Months } \\
\hline Brunet-Lézine developmental quotient & $101.1 \pm 8.4(195)$ & $101.7 \pm 8.4(99)$ & $100.4 \pm 8.4(96)$ \\
\hline \multicolumn{4}{|l|}{3 Years } \\
\hline McCarthy motor score & $55.0 \pm 12.2(126)$ & $55.2 \pm 12.4(96)$ & $54.3 \pm 11.2(30)$ \\
\hline McCarthy GCI & $122.8 \pm 16.2(126)$ & $124.0 \pm 15.2(96)$ & $118.9 \pm 18.7(30)$ \\
\hline \multicolumn{4}{|l|}{6 Years } \\
\hline
\end{tabular}

* Mean $\pm \operatorname{SD}(n)$.

There was no significant difference between the characteristics of children followed at 6 years and those lost to follow-up (nonparticipants). 
Table 3. Principal component analysis of the items from McCarthy motor scale at 3 and $6 y$ (Varimax rotation loadings)*

\begin{tabular}{lcc}
\hline & $\begin{array}{c}\text { First component } \\
\text { at } 3 \text { years } \\
\text { hand skill }\end{array}$ & $\begin{array}{c}\text { First component } \\
\text { at } 6 \text { years } \\
\text { hand skill }\end{array}$ \\
\hline Eigenvalues & 1.98 & 1.57 \\
Variance explained by factor (\%) & 40 & 32 \\
Coordination of arms & 0.70 & 0.66 \\
Copying of geometric patterns & 0.75 & 0.74 \\
Drawing of a man & 0.81 & 0.67 \\
Coordination of legs & 0.07 & 0.19 \\
Imitative action & 0.12 & -0.09
\end{tabular}

* Items that involve manual manipulation correlate with the first component. The hand skill score summarizes the $z$ scores of three items correlated with the first component at each age.

Table 4. Principal component analysis of biologic measures at birth (Varimax rotation)*

\begin{tabular}{lcc}
\hline & $\begin{array}{c}\text { First component } \\
\text { MONO }\end{array}$ & $\begin{array}{c}\text { Second component } \\
\text { ATP }\end{array}$ \\
\hline Eigenvalues & 1.51 & 1.02 \\
Variance explained by factor (\%) & 38 & 26 \\
$\mathrm{Na}^{+} \mathrm{K}^{+}$-ATPase & 0.06 & 0.77 \\
$\mathrm{Ca}^{2+} \mathrm{Mg}^{2+}$-ATPase & 0.07 & 0.74 \\
$\mathrm{HVA}$ & 0.81 & 0.13 \\
5-HIAA & 0.84 & 0.01
\end{tabular}

* The monoamine metabolites are correlated with the first component, and the ATPase activity measurements are correlated with the second component.

monoamine oxidation is increased at birth. The variables "child's sex" and "mother's educational level" influenced most of the psychometric scores. Because these four cofactors (child's sex, mother's educational level, duration of labor, and tea consumption) may have a potential influence on the relationships between the biologic and psychometric scores, they were included in subsequent multiple regression models.

Relationships between biochemical measures at birth and psychometric scores at 9 mo, $3 y$, and $6 y$. We did not find significant relationships between the ATPase and monoaminergic activities, and Brunet-Lézine developmental quotient at 9 mo of age ( $p>0.50$ for both), McCarthy GCI at $3 \mathrm{y}$ of age ( $p$ $>0.40$ and $p>0.80$, respectively), and the McCarthy $\mathrm{GCI}$ at $6 \mathrm{y}$ of age ( $p>0.30$ and $p>0.20$, respectively). The hand skill score at $6 \mathrm{y}$ of age was significantly negatively correlated with ATPase activities $\left(r=-0.21, p<0.05\right.$ for $\mathrm{Na}^{+} \mathrm{K}^{+}$-ATPase; and $r=-0.37, p<0.001$ for $\mathrm{Ca}^{2+} \mathrm{Mg}^{2+}$-ATPase; $\left.n=100\right)$ and with monoamine metabolite concentrations $(r=-0.32, p$ $<0.01, n=83$ and $r=-0.25, p<0.05, n=86$ for HVA and 5-HIAA, respectively).

The hand skill scores at 3 and at 6 y were negatively correlated with ATP score at birth $(r=-0.19, p<0.05$ and $r=-0.43, p<0.0001$, respectively). The hand skill score at 6 y was negatively correlated with MONO score $(r=-0.37$, $p<0.001)$, but not at $3 \mathrm{y}$ of age $(p>0.40)$. Table 5 summarizes these relations. The motor tasks not included in the hand skill score were not significantly correlated with MONO or ATP scores: the correlation coefficients between "leg coordination" or "imitative action" at $6 \mathrm{y}$ and ATP score were -0.09 and 0.09 , respectively; and for MONO score, -0.14 and 0.02 , respectively.
Table 5. Relationships between the ATP, MONO, and psychomotor scores at 9 mo, $3 y$, and $6 y$

\begin{tabular}{lll}
\hline & \multicolumn{1}{c}{ ATP score } & MONO score \\
\hline 9 mo & & \\
QD Brunet-Lezine & $\beta=0.16(\mathrm{NS}) \dagger$ & $\beta=-0.49(\mathrm{NS}) \dagger \dagger$ \\
3 y & $\beta=0.66(\mathrm{NS})$ & $\beta=-0.26(\mathrm{NS}) \dagger$ \\
McCarthy GCI & $\beta=-0.26^{*}$ & $\beta=-0.09(\mathrm{NS}) \dagger$ \\
Hand skill score & & \\
6 y & $\beta=-0.77$ (NS) & $\beta=-1.25(\mathrm{NS}) \dagger$ \\
McCarthy GCI & $\beta=-0.46^{* * *}$ & $\beta=-0.51^{* * \dagger}$ \\
\hline Hand skill score & $\beta$
\end{tabular}

$\beta$, unstandardized regression coefficient adjusted for child's sex, mother's educational level, and tea consumption.

$\dagger$ Additional adjustment for duration of labor.

$\$$ Additional adjustment for gestational age.

$* p<0.05 ; * * p<0.01 ; * * * p<0.001$.

In a multiple regression model in which hand skill score at $6 \mathrm{y}$ of age was the dependent variable and ATP and MONO scores were the independent variables, the ATPase and monoaminergic activities explained $29 \%$ of the hand skill score variance.

\section{DISCUSSION}

This epidemiologic study examined relationships between ATPase and monoaminergic activities with psychomotor performance among a healthy child population. Fine motor performance at 6 y of age, estimated by a hand skill score, was negatively related to ATPase activities and monoamine metabolite concentrations measured at birth. Precisely, ATPase activities and monoamine metabolite concentrations were shown to explain $29 \%$ of the hand skill score variance at $6 \mathrm{y}$ of age. However, motor performance at $3 \mathrm{y}$ of age was related to ATPase activities but not to monoamine metabolite concentrations, and motor performance measured at 9 mo was not related to any of these biologic measures.

Interestingly, the increase of HVA and 5-HIAA as a function of labor duration confirms the fact that the monoaminergic system reacts to birth stress, and that oxidation of monoamines increases at birth (31). Taking into account labor duration, the negative association between HVA and 5-HIAA levels and hand skill score at 6 y persisted. This may suggest an antenatal link between monoamines and motor development, which could be of genetic origin or depend on the intrauterine environment. Animal studies also showed that prenatal maternal stress alters the monoaminergic projections on the cortex and provokes behavioral disturbances that can persist into adulthood (1).

The increase of dopamine and serotonin liberation or increased MAO activity could contribute to enhanced HVA and 5-HIAA levels. MAO activity can be genetically predetermined and can also be influenced by the familial environment (32). However, the effect of the environment can be reduced in studies when the measurement is performed at birth. Newborns with a lower activity of MAO are reportedly more active (33). In healthy adults, a low MAO activity is associated with activation of the right cerebral hemisphere and frontal activity, which leads to motor disinhibition. In psychomotor tests, in- 
dividuals with low MAO activity manifest a preference for speed over precision (10). These observations support our hypothesis that monoamine metabolites measured at birth could be in part genetically predetermined by enzymatic activity, and therefore associated with subsequent manual performance of the child.

The selective correlation of monoamine metabolism and fine motor functions is in agreement with another study carried out on normal elderly people, among whom measures of concurrent plasma HVA were performed. This study showed that handwriting tests were the most sensitive in detecting dopamine deficiency in normal subjects (34). More recently, a positive association, independent of age, has been observed between fine motor performance and the number of dopamine receptors (35). These studies examine the association between concurrent levels of monoamines and fine motor performance. It is known that, in the developing brain, a temporary negative influence on the monoaminergic system could result in a permanently underdeveloped system (36). The observed relationship between MONO score and motor performance may be the result of genetic factors that translate a higher MAO activity during in utero and childhood life. Biomaterial was not collected through childhood because of ethical considerations. Further investigations are needed to elucidate the relationships between prenatal and postnatal activities of the monoaminergic and ATPase systems.

The strength of the correlation between $\mathrm{Ca}^{2+} \mathrm{Mg}^{2+}$-ATPase and hand skill score is remarkable. Contrary to the pathologic situation, as with hypoxia for example, in which inhibition of ATPases is caused by a primary energetic deficit or lipid peroxidation, in the physiologic conditions the cell activates the ATPase system for its metabolic needs. For example, an increase of intracellular calcium concentration leads to activation of available $\mathrm{Ca}^{2+} \mathrm{Mg}^{2+}$-ATPase molecules and to activation of their gene expression $(37,38)$. It is known that in the normal physiologic state the cell uses about $40 \%$ of ATP stock for only ATPase functioning. It may be suggested that this metabolic mechanism, excessive long-term activation of ATPases, could lead to a relative lack of ATP and deprive other cellular processes of energy sources. It is known also that cerebral zones involved in motor control, such as basal ganglia and the somatosensory cortex, are extremely sensitive to hypoxia in the perinatal period (39). We suggest that these zones may also be sensitive to energy deficit to a minimum or to intracellular calcium increase.

The lack of association between MONO or ATP scores and developmental quotient at 9 mo may be explained by two hypotheses. First, fine manual performances are in the process of being acquired at that age and cannot be well assessed. Second, Brunet-Lézine Scales are not specific tests for manual coordination and are not predictive of subsequent cognitive performances in the normal child (26). In an interim analysis of the present study, a weak and negative association between Brunet-Lézine Scales and HVA and 5-HIAA levels was reported (25). However, these interim analyses were based on data with a high number of missing values.

\section{CONCLUSIONS}

In summary, activities of the monoaminergic and membrane ATPase systems during the prenatal period are negatively associated with development of fine motor activities in children at age $6 \mathrm{y}$. This finding highlights the importance of prenatal factors influencing the monoaminergic and ATPase activities on motor development and could be explained by higher vulnerability of neuronal populations involved in visuomotor circuits to the effects of unknown factors influencing cationic membrane transport and monoamine degradation in utero. This finding may lead to further clinical and experimental research to better understand biochemical mechanisms involved in early cerebral development. Moreover, monoamine and ATPase measurements at birth may be a useful clinical tool to correlate with subsequent child psychomotor performances. This study also suggests that specific psychometric measures such as fine motor tests may be a better developmental measurement to correlate with biochemical measurements than general cognitive scales.

Our results highlight the importance of intrauterine functioning on monoaminergic and membrane ATPase systems in early human psychomotor development. Recently, it was demonstrated that development of motor circuits in humans is different from that in other species such as rodents and monkeys used in experimental studies, which underscores the need for an epidemiologic approach to estimate some of the factors involved in the development of the human motor system. Finally, given that an epidemiologic approach cannot support causal inferences and only shows associations, our findings need to be confirmed by experimental and other epidemiologic studies.

Acknowledgments. The authors thank the staff of the Robert Debré Maternity Clinic for its collaboration in obtaining specimens and the mothers for their participation.

\section{REFERENCES}

1. Berger-Sweeney J, Hohmann CF 1997 Behavioral consequences of abnormal cortical development: insights into developmental disabilities. Behav Brain Res 86:121-142

2. Yew DT, Chan WY 1999 Early appearance of acetylcholinergic, serotoninergic, and peptidergic neurons and fibers in the developing human central nervous system. Microsc Res Tech 45:389-400

3. Komori H, Matsuishi T, Yamada S, Ueda N, Yamashita Y, Kato H 1999 Effect of age on cerebrospinal fluid levels of metabolites of biopterin and biogenic amines. Acta Paediatr 88:1344-1347

4. Whitaker-Azmitia PM 1991 Role of serotonin and other neurotransmitter receptors in brain development: basis for developmental pharmacology. Pharmacol Rev 43:553561

5. Hadders-Algra M, Huisjes HJ, Touwen BCL 1988 Perinatal correlates of major and minor neurological dysfunction at school age: a multivariate analysis. Dev Med Child Neurol 30:472-481

6. Kapucu LO, Koç E, Gucuyener K, Zenciroglu A, Atalay Y, Unlu M, Van Royen E 1998 D2 receptor imaging with iodine-123-iodobenzamide brain SPECT in infants with hypoxic-ischemic brain injury. J Nucl Med 39:1703-1707

7. Lamers KJB, Wevers RA 1998 Abnormalities of biogenic amines affecting the metabolism of serotonin and catecholamines. Mult Scler 4:37-38

8. Weglage J, Pietsch M, Fünders B, Koch HG, Ullrich K 1995 Neurological findings in early treated phenylketonuria. Acta Paediatr 84:411-415

9. Stokes AH, Hastings TG, Vrana KE 1999 Cytotoxic and genotoxic potential of dopamine. J Neurosci Res 55:659-665

10. Klinteberg B, Oreland L, Hallman J, Wirsén A, Levander SE, Schalling D 1990-91 Exploring the connections between platelet monoamine oxydase activity and behavior: relationships with performance in neuropsychological tasks. Neuropsychobiology 23:188-196

11. Matthews G 1996 Neurotransmitters release. Annu Rev Neurosci 19:219-233 
12. Nicotera P, Bellomo G, Orrenius S 1992 Calcium-mediated mechanisms in chemically induced cell death. Annu Rev Pharmacol Toxicol 32:449-470

13. Carafoli E, Brini M 2000 Calcium pumps: structural basis for and mechanism of calcium transmembrane transport. Curr Opin Chem Biol 4:152-161

14. Garcia-Martin E, Gutierrez-Merino C 1996 Rate of $\mathrm{Na}^{+} / \mathrm{Ca}^{2+}$ exchange across the plasma membrane of synaptosomes measured using the fluorescence of chlortetracycline. Implications to calcium homeostasis in synaptic terminal. Biochim Biophys Acta 1280:257-264

15. Lees GJ 1991 Inhibition of sodium-potassium-ATPase: a potentially ubiquitous mechanism contributing to central nervous system neuropathology. Brain Res Rev $16: 283-300$

16. Constantino JN, Murphy DL 1996 Monoamine metabolites in "leftover" newborn human cerebrospinal fluid: a potential resource for biobehavioral research. Psychiatry Res 65:129-142

17. Constantino JN, Murphy DL, Morris JA 1999 Family psychiatric history, cerebrospinal fluid monoamine metabolites, and temperament in infants. Biol Psychiatry 45:626-632

18. Clarke RA, Murphy DL, Constantino JN 1999 Serotonin and externalizing behavior in young children. Psychiatry Res 86:29-40

19. Rapoport JL, Pandoni C, Renfield M, Lake CR, Ziegler MG 1977 Newborn dopamine- $\beta$-hydroxylase, minor physical anomalies, and infant temperament. Am J Psychiatry 134:676-678

20. Degrell I, Nagy E 1990 Correlations between cisternal CSF and plasma concentrations of HVA, MHPG, 5-HIAA, DA, and NA. Biol Psychiatry 27:1179-1182

21. Amin F, Davidson M, Davis KL 1992 Homovanillic acid measurement in clinical research: a review of methodology. Schizophr Bull 18:123-148

22. Sweadner KJ 1989 Isozymes of the Na/K-ATPase. Biochem Biophysic Acta 988:185-220

23. El-Mallakh RS, Wyatt RJ 1995 The Na,K-ATPase hypothesis for bipolar illness. Biol Psychiatry 37:235-244

24. Campagna D, Huel G, Hellier G, Girard F, Sahuquillo J, Fagot-Campagna A, Godin J, Blot P 2000 Negative relationships between erythrocyte Ca-pump activity and lead levels in mothers and newborns. Life Sci 68:203-215

25. Tang H.-W, Huel G, Campagna D, Hellier G, Boissinot C, Blot P 1999 Neurodevelopmental evaluation of 9-month-old infants exposed to low levels of lead in utero: involvement of monoamine neurotransmitters. J Appl Toxicol 19:167-172
26. Brunet O, Lézine I 1983 Le développement psychologique de la première enfance. EAP, Paris

27. McCarthy D 1976 Manuel des échelles d'aptitudes pour enfants de McCarthy M.S.C.A. Les Editions du Centre de Psychologie Appliquée, Paris

28. Lee HB, Comrey AL 1979 Distortions in a commonly used factor analytic procedure. Multivariate Behav Res 14:301-321

29. SAS/STAT User's Guide, Version 8. SAS Institute Inc, Cary NC, 1999

30. Flynn JR 1994 IQ gains over time. In: Sternberg RJ (ed) Encyclopedia of Human Intelligence. Macmillan, New York, pp 617-623

31. Gabriel M, Hunneman DH, Gahr M 1983 Plasma levels of catecholamine metabolites in the newborn period. Biol Neonate 44:203-209

32. Oxenstierna G, Edman G, Iselius L, Oreland L, Ross SB, Sedvall G 1986 Concentrations of monoamine metabolites in the cerebrospinal fluid of twins and unrelated individuals: a genetic study. J Psychiatr Res 20:19-29

33. Sostek AJ, Sostek AM, Murphy DL, Martin EB, Born WS 1981 Cord blood amine oxydase activities relate to arousal and motor functioning in human newborn. Life Sci 28:2561-2568

34. Amin F, Seeman TE, Mohs RC, Davidson M, Knott P, Berkman LF, Albert M, Blazer D 1994 Plasma homovanillic acid and performance on motor and cognitive tasks in community-dwelling elderly: MacArthur studies of successful aging. Neuropsychopharmacology 10:29-35

35. Volkow ND, Gur RC, Wang G-J, Fowler JS, Moberg PJ, Ding Y-S, Hitzemann R, Smith G, Logan J 1998 Association between decline in brain dopamine activity with age and cognitive and motor impairment in healthy individuals. Am J Psychiatry 155:344-349

36. Vitiello B, Jensen PS 1995 Developmental perspectives in pediatric psychopharmacology. Psychopharmacol Bull 31:75-81

37. Guerini D, Garcia-Martin E, Gerber A, Volbracht C, Leist M, Merino G, Carafoli E 1999 The expression of plasma membrane $\mathrm{Ca}^{2+}$ pump isoforms in cerebellar granule neurons is modulated by $\mathrm{Ca}^{2+}$. J Biol Chem 274:1667-1676

38. Zacharias DA, Strehler EE 1996 Change of plasma membrane $\mathrm{Ca}^{2+}$-ATPase splicevariant expression in response to a rise in intracellular $\mathrm{Ca}^{2+}$. Curr Biol 6:1642-1652

39. Martin LJ, Brambrink A, Koehler RC, Traystman RJ 1997 Primary sensory and forebrain motor systems in the newborn brain are preferentially damaged by hypoxiaischemia. J Comp Neurol 377:262-285 